\title{
Factors Predicting Therapeutic Efficacy of Combination Treatment With Sitagliptin and Insulin in Type 2 Diabetic Patients: The ASSIST-K Study
}

\author{
Masashi Ishikawa ${ }^{\mathrm{a}}$, Masahiko Takai ${ }^{\mathrm{a}}$, Hajime Maeda ${ }^{\mathrm{a}}$, Akira Kanamoria ${ }^{\mathrm{a}}$, Akira Kubota ${ }^{\mathrm{a}}$, Hikaru Amemiya ${ }^{\mathrm{a}}$, \\ Takashi Iizuka ${ }^{a}$, Kotaro Iemitsu ${ }^{a}$, Tomoyuki Iwasaki ${ }^{a}$, Goro Uehara ${ }^{a}$, Shinichi Umezawa ${ }^{a}$, Mitsuo Obana ${ }^{a}$, \\ Hideaki Kaneshige ${ }^{a}$, Mizuki Kaneshiro ${ }^{a}$, Takehiro Kawata ${ }^{a}$, Nobuo Sasai ${ }^{a}$, Tatsuya Saito ${ }^{\text {a }}$, Tetsuo Takuma ${ }^{a}$, \\ Hiroshi Takeda ${ }^{a}$, Keiji Tanaka ${ }^{a}$, Nobuaki Tsurui ${ }^{a}$, Shigeru Nakajima ${ }^{a}$, Kazuhiko Hoshino ${ }^{a}$, Shin Honda ${ }^{a}$, \\ Hideo Machimura ${ }^{a}$, Kiyokazu Matoba ${ }^{a}$, Fuyuki Minagawa ${ }^{a}$, Nobuaki Minamia, Yukiko Miyairia ${ }^{a}$, \\ Atsuko Mokubo ${ }^{a}$, Tetsuya Motomiya ${ }^{\mathrm{a}}$, Manabu Waseda ${ }^{\mathrm{a}}$, Masaaki Miyakawa ${ }^{\mathrm{a}}$, Yoshikazu Naka ${ }^{\mathrm{a}}$, \\ Yasuo Terauchi ${ }^{\mathrm{b}}$, Yasushi Tanakac ${ }^{\mathrm{c}}$, Ikuro Matsuba ${ }^{\mathrm{a}, \mathrm{d}}$
}

\begin{abstract}
Background: It is unclear whether dipeptidyl peptidase-4 inhibitors decrease hemoglobin $\mathrm{A}_{1 \mathrm{c}}\left(\mathrm{Hb}_{1 \mathrm{c}}\right)$ in a glucose-dependent manner in patients on insulin therapy who have impaired insulin secretion. This study investigated factors influencing the efficacy of sitagliptin when used concomitantly with insulin to treat type 2 diabetes mellitus (T2DM) in the real-world setting.
\end{abstract}

Methods: A retrospective study was conducted of 1,004 T2DM patients at 36 Japanese clinics associated with the Diabetes Task Force of the Kanagawa Physicians Association. Eligible patients had been on insulin for at least 6 months, with a baseline $\mathrm{HbA}_{1 \mathrm{c}}$ of $7.0 \%(53$ $\mathrm{mmol} / \mathrm{mol}$ ) or higher. Baseline characteristics and laboratory data from 495 patients were subjected to multiple regression analysis to identify factors influencing the change of $\mathrm{HbA}_{1 \mathrm{c}}$.

Results: Most patients $(\mathrm{n}=809)$ received sitagliptin at a dose of 50 mg. In the 1,004 patients, $\mathrm{HbA}_{1 \mathrm{c}}$ decreased by $0.74 \%(6 \mathrm{mmol} / \mathrm{mol})$ and body weight increased by $0.1 \mathrm{~kg}$ after 6 months of combination therapy. Multiple regression analysis showed that a higher baseline $\mathrm{HbA}_{1 \mathrm{c}}$, older age, and lower body mass index influenced the change of $\mathrm{HbA}_{1 \mathrm{c}}$ after 6 months. Hypoglycemic symptoms occurred in $7.4 \%$, but none were severe.

Conclusions: These results emphasize the importance of a higher

Manuscript accepted for publication March 19, 2015

aThe Study Group of the Diabetes Committee, Kanagawa Physicians Association, 3-1 Fujimi-cho, Naka-ku, Yokoyama City, Kanagawa 231-0037, Japan

${ }^{b}$ Department of Endocrinology and Metabolism, Yokohama City University, 3-9 Fukuura, Kanazawa-ku, Yokohama 236-0004, Japan

'Division of Metabolism and Endocrinology, Department of Internal Medicine, St. Marianna University School of Medicine, 2-16-1 Sugao, Miyamaeku, Kawasaki City, Kanagawa 216-8511, Japan

${ }^{\mathrm{d} C o r r e s p o n d i n g ~ A u t h o r: ~ I k u r o ~ M a t s u b a, ~ M a t s u b a ~ M e d i c a l ~ C l i n i c, ~ 2-159 ~ T s u k-~}$ agoshi, Saiwai-ku, Kawasaki City, Kanagawa 212-0024, Japan.

Email: ikuro@matsuba-web.com

doi: http://dx.doi.org/10.14740/jocmr2149w
$\mathrm{HbA}_{1 \mathrm{c}}$ at the commencement of sitagliptin therapy in patients on insulin. Glucose-dependent suppression of glucagon secretion by sitagliptin may be useful in patients with impaired insulin secretion. Sitagliptin can be used concomitantly with insulin irrespective of the insulin regimen, duration of insulin treatment, and concomitant medications.

Keywords: Type 2 diabetes; Sitagliptin; Insulin; Combination therapy; $\mathrm{HbA}_{1 \mathrm{c}}$; Multiple regression analysis; Body weight

\section{Introduction}

Among the dipeptidyl peptidase-4 (DPP-4) inhibitors that are widely used, sitagliptin is the first to be approved for patients with type 2 diabetes mellitus (T2DM) on insulin therapy. Despite its established position, relatively few clinical studies of sitagliptin have been performed. These include a US study of patients who were predominantly on once-daily long-acting, insulin therapy [1], a Japanese study of patients on mixed insulin therapy [2], and observational studies with small populations [3, 4].

T2DM patients receiving insulin often have a longer disease duration and a reduced insulin secretion capacity. Because their baseline characteristics and insulin doses vary, clinical trials alone do not provide enough information about these patients [5]. Moreover, the effectiveness of DPP-4 inhibitors at stimulating an insulin response in patients with compromised insulin secretion on insulin therapy has not been examined. A small-scale randomized controlled trial (RCT) has shown that sitagliptin improves hemoglobin $\mathrm{A}_{1 \mathrm{c}}\left(\mathrm{HbA}_{1 \mathrm{c}}\right)$ and postprandial glucose levels in patients with type 1 diabetes [6]. The effect of sitagliptin in increasing glucagon-like peptide 1 (GLP-1), which results in inhibition of glucagon secretion rather than stimulation of insulin secretion, has attracted attention [7, 8].

RCTs play a significant role in evidence-based medicine. However, such trials exclude patients who do not meet the specified inclusion criteria, even though these patients are often important in the real-world clinical setting. This is particu- 
Table 1. Characteristics of the Subjects

\begin{tabular}{|c|c|}
\hline Age, years & $63.9 \pm 12.1$ \\
\hline Sex, male/female & $521 / 483$ \\
\hline Body mass index & $25.5 \pm 4.6$ \\
\hline Hemoglobin $\mathrm{A}_{1 \mathrm{c}}, \%(\mathrm{mmol} / \mathrm{mol})$ & $8.69 \pm 1.31(72 \pm 12)$ \\
\hline Fasting blood glucose, $\mathrm{mg} / \mathrm{dL}(\mathrm{mmol} / \mathrm{L})$ & $184.3 \pm 70.5(10.23 \pm 3.91)$ \\
\hline Serum C-peptide, ng/mL (nmol/L) & $1.47 \pm 1.03(0.49 \pm 0.34)$ \\
\hline Duration of diabetes, years & $17.1 \pm 9.0$ \\
\hline Duration of insulin treatment, years & $6.3 \pm 5.6$ \\
\hline Smoking, \% & 23.1 \\
\hline Alcohol consumption, $\%$ & 22.7 \\
\hline \multicolumn{2}{|l|}{ Complications, $\%$} \\
\hline Diabetic neuropathy & 33.6 \\
\hline Diabetic retinopathy & 33.4 \\
\hline Diabetic nephropathy & 38.5 \\
\hline Cerebrovascular disease & 7.6 \\
\hline Myocardial infarction/angina pectoris & 17.3 \\
\hline Arteriosclerosis obliterans & 8.8 \\
\hline Hypertension & 57.7 \\
\hline Dyslipidemia & 61.4 \\
\hline Hepatic steatosis & 30.0 \\
\hline \multicolumn{2}{|l|}{ Insulin regimen, $\mathrm{n}$} \\
\hline Long-acting insulin, once daily & 215 \\
\hline Mixed insulin, twice daily & 162 \\
\hline Three times daily, no long-acting insulin & 209 \\
\hline Basal-bolus insulin & 334 \\
\hline \multicolumn{2}{|l|}{ Concomitant oral medications, $\mathrm{n}$} \\
\hline Sulfonylureas & 222 \\
\hline Biguanides & 397 \\
\hline Thiazolidinediones & 64 \\
\hline Alpha-glucosidase inhibitors & 184 \\
\hline None & 418 \\
\hline \multicolumn{2}{|l|}{ Dose of sitagliptin, $n$} \\
\hline $25 \mathrm{mg}$ throughout & 65 \\
\hline Up-titration from $25 \mathrm{mg}$ to $50 \mathrm{mg}$ & 83 \\
\hline $50 \mathrm{mg}$ throughout & 809 \\
\hline Up-titration from $50 \mathrm{mg}$ to $100 \mathrm{mg}$ & 47 \\
\hline
\end{tabular}

Data are mean \pm standard deviation unless otherwise indicated.

larly relevant for T2DM, since pathological conditions vary widely in patients with this disease, making it difficult to investigate all patient types in a single RCT.

In the present study, we investigated the efficacy and safety of insulin-sitagliptin combination therapy in a multicenter study to verify the usefulness of this regimen for T2DM patients on various types of insulin therapy. Our findings add some useful information to the evidence already established by RCTs.

\section{Methods}

This retrospective study included patients receiving sitagliptin in addition to insulin from November 2011 to March 2013 at 36 diabetes clinics in Kanagawa Prefecture, Japan. Sitagliptin was started if the attending physician considered that insulin was not achieving adequate glycemic control. Glycemic control, the insulin dose, concomitant drugs, blood pressure (BP), body weight, and laboratory data were analyzed, as well as the occurrence of adverse events. Eligible patients had been on insulin for 6 months or longer, with an $\mathrm{HbA}_{1 \mathrm{c}}$ of $7.0 \%$ (53 $\mathrm{mmol} / \mathrm{mol}$ ) or higher, and had undergone follow-up for at least 6 months.

The primary endpoint was the change of $\mathrm{HbA}_{1 \mathrm{c}}$. To explore factors contributing to the improvement of $\mathrm{HbA}_{1 \mathrm{c}}$ by insulin-sitagliptin combination therapy, multiple regression analysis was performed with the following variables: age, sex, baseline body mass index (BMI), duration of insulin therapy, baseline $\mathrm{HbA}_{1 \mathrm{c}}$, daily insulin dose, presence/absence of diabetic neuropathy, smoking, alcohol consumption, and concomitant use of sulfonylureas (SUs), biguanides (BGs), alpha-glucosidase inhibitors ( $\alpha$-GIs), and thiazolidinediones (TZDs). Patients who had previously been treated with a DPP-4 inhibitor were excluded.

Results are reported as mean \pm standard deviation. All analyses were carried out using SPSS version 19 software (SPSS Inc., Chicago, IL, USA). The effect of sitagliptin treatment was assessed by one-way analysis of variance and $\mathrm{P}<$ 0.05 was accepted as indicating statistical significance.

This study was registered with the Clinical Trials Registry (http://clinicaltrials.gov; NCT01855087) and was undertaken in accordance with the Ethical Guidelines for Clinical Studies of the Japanese Ministry of Health, Labor, and Welfare. Informed consent was not required because this was a retrospective analysis.

\section{Results}

A total of 1,169 case record forms were collected. Then patients with sitagliptin treatment for $<6$ months $(\mathrm{n}=54)$, baseline $\mathrm{HbA}_{1 \mathrm{c}}<7.0 \%(53 \mathrm{mmol} / \mathrm{mol})(\mathrm{n}=81)$, and incomplete data $(\mathrm{n}=30)$ were excluded. The remaining 1,004 patients were available for analysis and their characteristics are shown in Table 1. Based on the results of Japanese clinical studies employing sitagliptin, the drug was up-titrated in some patients from a starting dose of $50 \mathrm{mg}$ to $100 \mathrm{mg}$ if the former dose was not effective, while a low dose of $25 \mathrm{mg}$ was selected for 65 patients with impaired renal function [9]. Among the 1,004 patients, medications other than insulin and sitagliptin were altered in 185 patients, including 144 who discontinued $\alpha$-GIs or TZDs and 41 who received add-on biguanides.

After starting insulin-sitagliptin combination therapy, $\mathrm{HbA}_{1 \mathrm{c}}$ decreased significantly from the baseline value of 8.69 $\pm 1.31 \%(72 \pm 12 \mathrm{mmol} / \mathrm{mol})$ to $8.30 \pm 1.23 \%(67 \pm 11 \mathrm{mmol} /$ $\mathrm{mol}), 7.99 \pm 1.25 \%(64 \pm 11 \mathrm{mmol} / \mathrm{mol})$, and $7.95 \pm 1.25 \%(64$ $\pm 11 \mathrm{mmol} / \mathrm{mol}$ ) at 1 month, 3 months, and 6 months, respectively. Body weight showed a slight, but significant, increase 

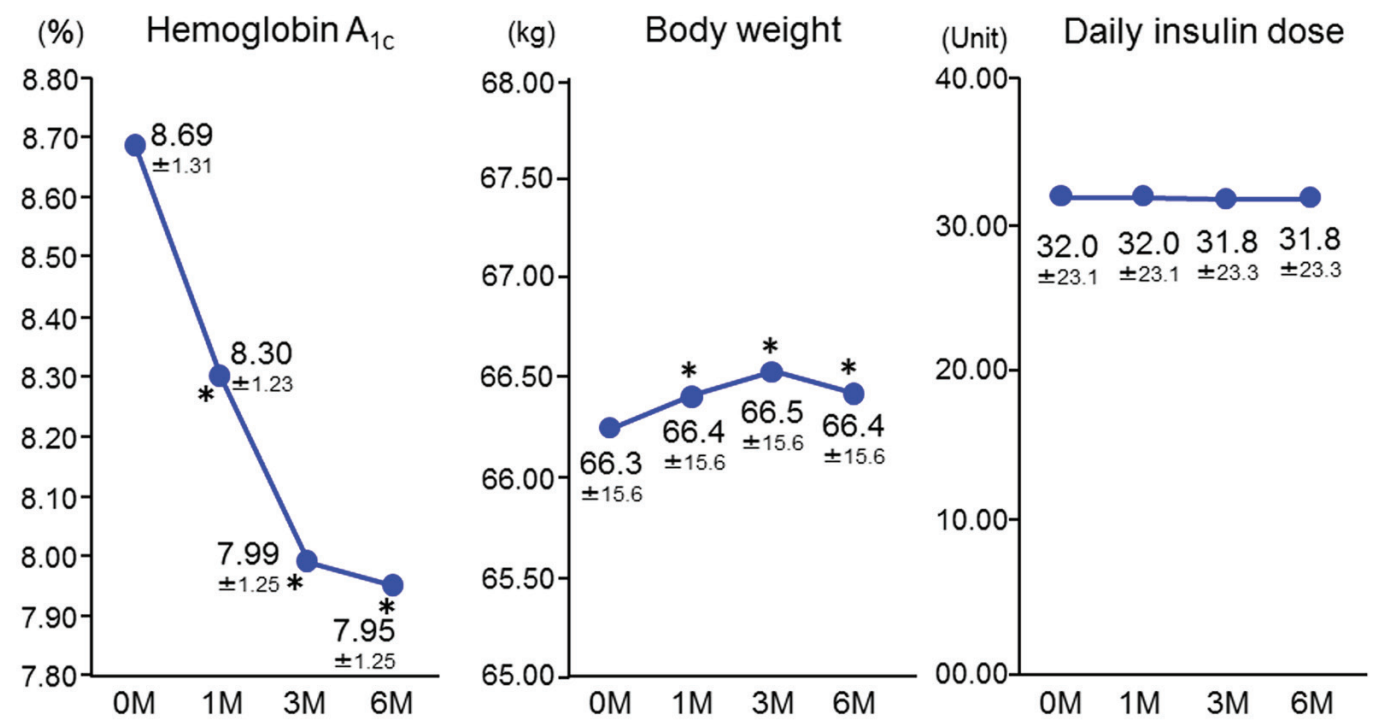

Figure 1. Changes in hemoglobin $A_{1 c}$, body weight, and insulin dose $(n=1,004)$. Data are the mean \pm standard deviation. Analysis of variance vs. baseline. ${ }^{*} \mathrm{P}<0.05$. M: months.

of $0.1 \mathrm{~kg}$, while there were no changes in the doses of insulin or the other oral antidiabetic drugs (Fig. 1).

Hypoglycemic symptoms were noted in $7.4 \%$ of the subjects, but were not severe. Other adverse events included abdominal distension $(0.9 \%)$ and constipation $(0.4 \%)$. With regard to changes in laboratory values, there was a significant decrease of systolic BP, fasting blood glucose, glycated albumin, alkaline phosphatase, total cholesterol, high-density lipoprotein (HDL) cholesterol, and triglycerides, while there was a significant increase of uric acid and serum creatinine (Table 2).

Multiple regression analysis was performed to examine factors related to the change of $\mathrm{HbA}_{1 \mathrm{c}}$ within 6 months of starting sitagliptin. Complete baseline data on the age, sex, BMI, duration of insulin treatment, $\mathrm{HbA}_{1 \mathrm{c}}$, daily insulin dose, presence/absence of diabetic neuropathy, smoking, alcohol consumption, and concomitant use of SUs, BGs, $\alpha$-GIs and TZDs were available for 495 patients. These characteristics of the 495 patients were similar to those of the main study population (data not shown).

A high $\mathrm{HbA}_{1 \mathrm{c}}$ at baseline was the strongest contributor to reduction of $\mathrm{HbA}_{1 \mathrm{c}}$ at 6 months after starting treatment with insulin-sitagliptin combination therapy (Table 3 ). In addition, BMI and age made slight, but significant, contributions to the reduction of $\mathrm{HbA}_{1 \mathrm{c}}$ (Table 3 ).

We also performed multiple regression analysis on a cohort of 114 patients who had C-peptide data before commencement of sitagliptin therapy. This showed that C-peptide had no influence on the effectiveness of sitagliptin (data not shown).

\section{Discussion}

The Diabetes Task Force of the Kanagawa Physicians Association previously conducted a large-scale trial involving more than 1,000 patients (the ASSET-K study), which established that a higher baseline $\mathrm{HbA}_{1 \mathrm{c}}$, shorter disease duration, and lower baseline BMI were factors contributing to reduction of $\mathrm{HbA}_{1 \mathrm{c}}$ in patients receiving sitagliptin combined with another oral antidiabetic drug [10-14]. However, the factors influencing the $\mathrm{HbA}_{1 \mathrm{c}}$-lowering effect of sitagliptin when it is used concomitantly with insulin were not fully elucidated. Therefore, we conducted the present study to investigate this issue.

We confirmed the effectiveness and safety of combining sitagliptin with insulin in a large patient population $(\mathrm{n}=$ $1,004)$ treated in the real-world setting. $\mathrm{HbA}_{1 \mathrm{c}}$ decreased by $0.74 \%(6 \mathrm{mmol} / \mathrm{mol})$ and body weight increased by $0.1 \mathrm{~kg}$, while there were no appreciable changes in the doses of insulin or other oral antidiabetic agents. In addition, there were no episodes of severe hypoglycemia, although hypoglycemic events were reported in $7.4 \%$ of the patients. In general, the formulation, dose, and frequency of insulin administration are altered if an $\mathrm{HbA}_{1 \mathrm{c}}<7.0 \%(53 \mathrm{mmol} / \mathrm{mol})$ is not achieved after a certain period. However, increasing the insulin dose may lead to adverse events such as weight gain and hypoglycemia. The present study demonstrated the effectiveness of insulinsitagliptin combination therapy in the real-world setting. As well as improving $\mathrm{HbA}_{1 \mathrm{c}}$, there were significant reductions of systolic BP, fasting blood glucose, glycated albumin, alkaline phosphatase, total cholesterol, HDL cholesterol, and triglycerides, which suggest that sitagliptin may also exert a favorable effect on BP and the lipid profile, as reported in the ASSET-K study [14]. The significant increase of uric acid and serum creatinine were also in agreement with the results of the ASSET-K study, and can be explained by the fact that sitagliptin increases GLP-1, an incretin hormone with diuretic properties. In fact, a correlation between the reduction of BP and an increase of creatinine and uric acid levels has been reported [14]. 
Table 2. Changes in Laboratory Values

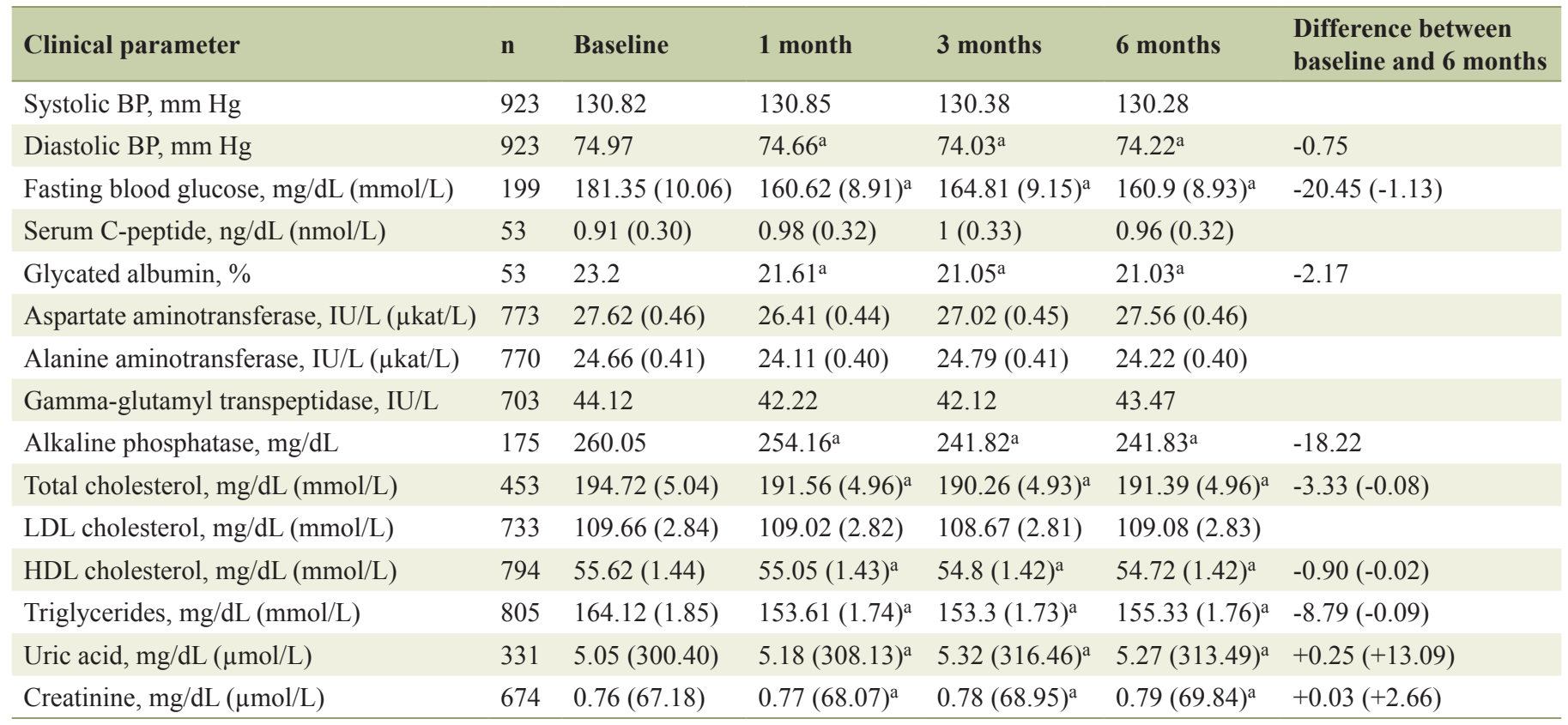

aP $<0.05$ (analysis of variance vs. baseline). BP: blood pressure; HDL: high-density lipoprotein; LDL: low-density lipoprotein.

We performed multiple regression analysis to identify patients who were likely to respond to addition of sitagliptin to insulin therapy. We analyzed various factors that had a potential influence on $\mathrm{HbA}_{1 \mathrm{c}}$ including diabetic neuropathy, smoking, and alcohol, because diabetic neuropathy may inhibit the effect of GLP-1 and patients who smoke or drink regularly are more likely to lead an unhealthy lifestyle with suboptimal diet and exercise. We identified a higher baseline $\mathrm{HbA}_{1 \mathrm{c}}$ as the strongest contributing factor, while a lower baseline BMI and older age were also significant. This is in agreement with the fact that older patients tended to have a lower BMI in our study. There was a positive correlation between the duration of diabetes and the duration of insulin therapy (Pearson's correlation coefficient $=0.40$ ), as well as between the frequency of insulin administration and the daily insulin dose (Pearson's correlation coefficient $=0.51$ ). Therefore, the duration of insulin therapy and the daily insulin dose were included in the multiple regression analysis as background factors, revealing that the duration of insulin therapy was not associated with the effectiveness of sitagliptin. These results support the addition of sitagliptin to insulin therapy, irrespective of the duration of insulin treatment, the daily insulin dose, concomitant

Table 3. Multiple Regression Analysis of Delta Hemoglobin $A_{1 c}$ After 6 Months of Insulin-Sitagliptin Combination Therapy in 495 Patients With Complete Data

\begin{tabular}{llll}
\hline Factor & Beta value & P value & Standardized beta value \\
\hline Age & -0.010 & 0.0088 & -0.124 \\
Female sex & 0.164 & 0.0802 & 0.080 \\
Baseline body mass index & 0.030 & 0.0048 & 0.136 \\
Duration of insulin treatment, years & 0.013 & 0.1383 & 0.065 \\
Baseline hemoglobin $\mathrm{A}_{1 \mathrm{c}}$ & -0.400 & $<0.0001$ & -0.502 \\
Baseline daily insulin dose & 0.002 & 0.2401 & 0.057 \\
Presence of diabetic neuropathy & 0.051 & 0.5512 & 0.025 \\
Smoking, yes & 0.004 & 0.9694 & 0.002 \\
Alcohol consumption, yes & -0.004 & 0.9683 & -0.002 \\
Sulfonylureas & 0.191 & 0.0939 & 0.074 \\
Biguanides & -0.162 & 0.0720 & -0.078 \\
Thiazolidinediones & -0.300 & 0.0800 & -0.072 \\
Alpha-glucosidase inhibitors & -0.096 & 0.3606 & -0.037 \\
\hline
\end{tabular}


medications, and the C-peptide profile. Even in patients with compromised insulin secretion, sitagliptin can still effectively stimulate insulin secretion and it also has other potential benefits. Inhibition of glucagon secretion may be involved in the efficacy of DPP-4 inhibitors for insulin-treated patients [6] and inhibition of glucagon secretion as a GLP-1 receptor agonist may be important in type 1 diabetes [15].

It has been reported that T2DM patients in East Asian countries (including Japan) have lower endogenous insulin secretion and that their BMI tends to be lower [16]. Kim et al reported that sitagliptin was particularly effective in the Japanese population [17]. In addition to the ASSET-K study, several observational studies have demonstrated the effectiveness of sitagliptin in patients with a lower BMI [11, 13, 18]. However, more research is needed to determine whether our results are related to ethnic factors, especially studies in nonJapanese populations.

There were some limitations of this study. First, it was retrospective. Second, all of the patients received sitagliptin and there was no control group without sitagliptin treatment. Third, markers for the assessment of beta-cell function (HOMA-beta) and the basal level of active GLP-1, which are factors that could influence the reduction of $\mathrm{HbA}_{1 \mathrm{c}}$ by sitagliptin therapy, were not measured in all patients. In fact, only 495 out of 1,004 patients were included in the detailed analysis, but these patients were considered to be reasonably representative of the entire population since their characteristics did not differ from those of the whole population (data not shown).

In conclusion, this study provided useful new information about the efficacy and safety of sitagliptin that can be added to the findings of relevant RCTs. We demonstrated that a higher baseline $\mathrm{HbA}_{1 \mathrm{c}}$ was associated with greater improvement of $\mathrm{HbA}_{1 \mathrm{c}}$ in patients given sitagliptin as add-on therapy to insulin, while other factors were not clinically relevant. This suggests that patients might be candidates for add-on sitagliptin therapy irrespective of their characteristics, insulin dose, and concomitant medications. Because a significant increase of body weight was not observed, sitagliptin may be added whenever the $\mathrm{HbA}_{1 \mathrm{c}}$ is not well controlled by insulin therapy.

\section{Acknowledgement}

The authors would like to thank the members of the Kanagawa Physicians Association.

\section{Competing Interests}

MI, MT, and IM have received lecture fees from MSD K.K. and Ono Pharmaceutical, Co., Ltd.

\section{Grant Support}

This research was financially supported by the Kidney Foundation, Japan.

\section{References}

1. Umpierrez GE, Gianchandani R, Smiley D, Jacobs S, Wesorick DH, Newton C, Farrokhi F, et al. Safety and efficacy of sitagliptin therapy for the inpatient management of general medicine and surgery patients with type 2 diabetes: a pilot, randomized, controlled study. Diabetes Care. 2013;36(11):3430-3435.

2. Katsuno T, Ikeda H, Ida K, Miyagawa J, Namba M. Addon therapy with the DPP-4 inhibitor sitagliptin improves glycemic control in insulin-treated Japanese patients with type 2 diabetes mellitus. Endocr J. 2013;60(6):733-742.

3. Shimoda S, Iwashita S, Ichimori S, Matsuo Y, Goto R, Maeda T, Matsuo T, et al. Efficacy and safety of sitagliptin as add-on therapy on glycemic control and blood glucose fluctuation in Japanese type 2 diabetes subjects ongoing with multiple daily insulin injections therapy. Endocr J. 2013;60(10):1207-1214.

4. Mori Y, Taniguchi Y, Miyazaki S, Yokoyama J, Utsunomiya K. Effects of add-on treatment with sitagliptin on narrowing the range of glucose fluctuations in Japanese type 2 diabetes patients receiving insulin therapy. Diabetes Technol Ther. 2013;15(3):237-240.

5. Kadowaki T, Tajima N, Odawara M, Minamide T, Kawashima M, Yanagida D, Okamoto T, et al. Efficacy and safety of sitagliptin add-on therapy in Japanese patients with type 2 diabetes on insulin monotherapy. Diabetol Int. 2013;4:160-172.

6. Ellis SL, Moser EG, Snell-Bergeon JK, Rodionova AS, Hazenfield RM, Garg SK. Effect of sitagliptin on glucose control in adult patients with Type 1 diabetes: a pilot, double-blind, randomized, crossover trial. Diabet Med. 2011;28(10):1176-1181.

7. Watanabe K, Kobayashi K, Takemoto M, Ishibashi R, Yamaga M, Kawamura H, Fujimoto M, et al. Sitagliptin improves postprandial hyperglycemia by inhibiting glucagon secretion in Werner syndrome with diabetes. Diabetes Care. 2013;36(8):e119.

8. Chen B, Moore A, Escobedo LV, Koletsky MS, Hou D, Koletsky RJ, Ernsberger P. Sitagliptin lowers glucagon and improves glucose tolerance in prediabetic obese SHROB rats. Exp Biol Med (Maywood). 2011;236(3):309-314.

9. Iwamoto Y, Taniguchi T, Nonaka K, Okamoto T, Okuyama K, Arjona Ferreira JC, Amatruda J. Dose-ranging efficacy of sitagliptin, a dipeptidyl peptidase-4 inhibitor, in Japanese patients with type 2 diabetes mellitus. Endocr J. 2010;57(5):383-394.

10. Maeda H, Kubota A, Tanaka Y, Terauchi Y, Matsuba I. The safety, efficacy and predictors for HbAlc reduction of sitagliptin in the treatment of Japanese type 2 diabetes. Diabetes Res Clin Pract. 2012;95(1):e20-22.

11. Maeda H, Kubota A, Kanamori A, Tanaka Y, Terauchi Y, Matsuba I. Long-term efficacy and safety of sitagliptin in the treatment of Japanese Type 2 diabetes (ASSET$\mathrm{K} 1)$ to a target of $\mathrm{HbA} 1 \mathrm{c}<7 \%$. J Endocrinol Invest. 2013;36(8):568-573.

12. Kanamori A, Matsuba I. Factors associated with reduced efficacy of sitagliptin therapy: analysis of 93 patients with 
type 2 diabetes treated for 1.5 years or longer. J Clin Med Res. 2013;5(3):217-221.

13. Kubota A, Maeda H, Kanamori A, Matoba K, Jin Y, Minagawa F, Obana M, et al. Efficacy and safety of sitagliptin monotherapy and combination therapy in Japanese type 2 diabetes patients. J Diabetes Investig. 2012;3(6):503509.

14. Kubota A, Maeda H, Kanamori A, Matoba K, Jin Y, Minagawa $\mathrm{F}$, Obana $\mathrm{M}$, et al. Pleiotropic effects of sitagliptin in the treatment of type 2 diabetes mellitus patients. J Clin Med Res. 2012;4(5):309-313.

15. Kielgast U, Krarup T, Holst JJ, Madsbad S. Four weeks of treatment with liraglutide reduces insulin dose without loss of glycemic control in type 1 diabetic patients with and without residual beta-cell function. Diabetes Care. 2011;34(7):1463-1468.

16. Kim YG, Hahn S, Oh TJ, Kwak SH, Park KS, Cho YM. Differences in the glucose-lowering efficacy of dipeptidyl peptidase-4 inhibitors between Asians and non-Asians: a systematic review and meta-analysis. Diabetologia. 2013;56(4):696-708.

17. Park H, Park C, Kim Y, Rascati KL. Efficacy and safety of dipeptidyl peptidase-4 inhibitors in type 2 diabetes: metaanalysis. Ann Pharmacother. 2012;46(11):1453-1469.

18. Kim SA, Shim WH, Lee EH, Lee YM, Beom SH, Kim ES, Yoo JS, et al. Predictive clinical parameters for the therapeutic efficacy of sitagliptin in korean type 2 diabetes mellitus. Diabetes Metab J. 2011;35(2):159-165. 